\title{
Electrodeposition and Corrosion Protection Performance of Polypyrrole Composites on Aluminum
}

\author{
Mahmoud A. Hussein", Salih S. Al-Juaid, Bahaa M. Abu-Zied, Abou-Elhagag A. Hermas ${ }^{*}$ \\ Chemistry Department, Faculty of Science, King Abdulaziz University, Jeddah 21589, Saudi Arabia \\ *E-mail: mahussein74@yahoo.com, hagag 99@yahoo.com
}

doi: $10.20964 / 11049$

Received: 25 January 2016 / Accepted: 3 March 2016 / Published: 1 April 2016

\begin{abstract}
Electrodeposition of PPy-sCNTs and PANI-NiLa nanocomposites have been formed on aluminum using cyclic voltammetry technique. The process has been carried out from aqueous solution of $0.4 \mathrm{M}$ oxalic acid containing $0.2 \mathrm{M}$ pyrrole as a monomer and additives of nanopatricle materials. Presence of sCNT and $\mathrm{Ni}_{2} \mathrm{LaO}_{4}$ (NiLa oxide) nanoparticles in the electrolyte increased the electrodeposition rate of the PPy, the NiLa nanoparticles increased the deposition largely within the first fifty cycle. SEM images indicated emerging of the nanoparticles materials in the polymer layer forming nanocomposites. The sCNTs increased the thermal stability of PPy while the NiLa oxide nanoparticles decreased this stability. Improvements in the adhesion and protection role of the PPy coating for Al substrate were obtained in presence of sCNT and PPy-NiLa particles. All prepared nanocomposites layers protected $\mathrm{Al}$ better than that of PPy layer in $\mathrm{NaCl}$ solution. The highest protection was obtained by PPy-NiLa nanocomposite coating. The role of nanoparticles in the PPy coating and protection of Al was discussed.
\end{abstract}

Keywords: Conductive polymer, Electrodeposition, Polypyrrole, Protective coating, nanoparticles, nanocompsite

\section{FULL TEXT}

(C) 2016 The Authors. Published by ESG (www.electrochemsci.org). This article is an open access article distributed under the terms and conditions of the Creative Commons Attribution license (http://creativecommons.org/licenses/by/4.0/). 